\title{
Use of Herbs or Nutrient Supplements as a Complementary and Traditional Medicine Product in Pediatric Hematology Patients
}

\section{Çocuk Hematoloji Kliniği’nde İzlenen Hastalarda Tamamlayıcı ve Geleneksel Tıp Ürünü Olarak Besin Desteği veya Bitkisel Tedavilerin Kullanımı}

\author{
Turan Bayhan', Mualla Çetin ${ }^{1}$, Fatma Gümrük ${ }^{1}$, Özlem Şatırer², Pınar Kahyaoğlu ${ }^{2}$, Şule Ünal ${ }^{1}$ \\ ${ }^{1}$ Çocuk Hematoloji Bilim Dalı, Hacettepe Üniversitesi Tıp Fakültesi \\ ${ }^{2}$ Çocuk Sağlı̆̆ı ve Hastalıkları Anabilim Dalı, Hacettepe Üniversitesi Tıp Fakültesi
}

Dergiye Ulaşma Tarihi: 05.10.2018 Dergiye Kabul Tarihi: 07.11.2018 Doi: 10.5505/aot.2019.16362

\begin{abstract}
ÖZET
GíRiş ve AMAÇ: Tamamlatıcı ve geleneksel tıp (TGT) ürünleri, çocukluk çağı döneminde birçok kronik hastalıkta modern tedavinin yanında aileler tarafindan kullanılabilmektedir. Özellikle beslenme ürünleri ve bitkisel tedaviler TGT uygulamaları içinde sık kullanılan, yan etki ve ilaç etkileşimi gelişme riski yüksek olanlardır. Çalışmamızda çocukluk çağı yaş grubu hematoloji hastalarında beslenme ürünleri ve bitkisel tedavi kullanım sıklığı ve ilişkili faktörleri incelemeyi amaçladık.

YÖNTEM ve GEREÇLER: Çocuk Hematoloji Kliniği'nde takip edilen hematolojik kanser veya kronik hematolojik hastalı̆̆ı olan $1-20$ yaş arası 138 hastanın ebeveynlerinden çalışma anketlerini doldurmaları istendi.

BULGULAR: Yaş ortancası 9 (1 - 20) y1l olan hastaların 91'i $(\% 65,9)$ maliyn, 47'si $(\% 34,1)$ beniyn bir tanıyla izlenmekteydi. Yetmiş bir $(\% 51,4)$ hasta en az bir TGT beslenme ürünü kullanırken $67(\% 48,6)$ hasta böyle bir ürün hiç kullanmamıştı. Hastaların 47'si sadece bir ürün, 20'si iki ve dördü üç ürün kullanmıştı. Toplamda 21 çeşit ürün kullanıldığı öğrenildi. En sık kullanılan beş ürün; keçiboynuzu pekmezi (39 hasta), arı sütü (13 hasta), üzüm çekirdeği ekstresi (9 hasta), üzüm pekmezi (7 hasta) ve polendi (6 hasta). Yirmi yedi hastada (\%38) ürünlerin doktorlarının bilgisi dışında kullandığı öğrenildi. Hasta tanılarının beniyn veya maliyn olasına göre beslenme ürünü kullanımı karşılaştırıldığında istatistiksel olarak anlamlı şekilde maliyn tanılı hastalarda beniynlere göre kullanımın daha fazla olduğu görüldü (sırasılya; \%61,5, \%31,9, $p ; 0,001$ ).

TARTIŞMA ve SONUÇ: Çocukluk çağında hematoloji hastaları arasında özellikle maliyn bir tanıya sahip olanlarda bitkisel tedavi ve beslenme desteği kullanımı sıktır ve bir kısmından hastaların sorumlu doktorlarının da haberi yoktur. Hastaların kliniklerde takiplerinde bu tür destekler alıp almadıklarının rutinde sorulmalı, hastaların kullandıkları ürünler hakkında önyargıdan uzak rasyonel öneriler verilmelidir.
\end{abstract}

Anahtar Kelimeler: Beslenme desteği, bitkisel tedavi, çocuk, hematoloji, tamamlayıcı ve geleneksel tıp

\begin{abstract}
INTRODUCTION: Complementary and traditional medicine (CTM) has been used in many chronic diseases during childhood by parents. Herbal medicines and nutrient supplements are the most common used CTM therapies, besides they have increased risk of side effects and drug interaction. In our study, we aimed to investigate frequency of herbal medicine and nutrient supplement usage and associated factors in pediatric patients with hematological diseases.

METHODS: Parents of 138 children with a hematological cancer or chronic hematological disease who were between $1-20$ years of age filled the study questionnaire.

RESULTS: Median age of patients were $9(1-20)$ years, $91(65.9 \%)$ of patients were with malign and 47 $(34.1 \%)$ of patients were with benign diseases. Seventy one (51.4\%) of patients have used minimum one CTM nutrient supplement or herbal medicine. Forty seven patients used only one product, 20 patients used two products and four of the patients used three products. Totally 21 kinds of CTM therapies have been used. Most commonly used five herbal medicine and nutrients supplements were; carob molasses (39 patients), gelee royale (13 patients), grape seed extract ( 9 patients), grape molasses ( 7 patients), and pollen (6 patients). Twenty seven (38\%) of patients used products without permission of their doctors. When we compared frequency of CTM nutrient support or herbal medicine usage in patients with malign and benign diseases, statistically significantly patients with malign diseases have tendency to utilize these products $(61.5 \%, 31.9 \%, p ; 0.001$, respectively).
\end{abstract}


DISCUSSION and CONCLUSION: Herbal medicine and nutrient support usage is common in pediatric patients with hematological diseases, especially if patients have malign diseases. Some of the patients have been using these products without permission of their responsible doctors. During follow-up of patients with hematological diseases doctors should ask patients if they use CTM therapies, and should give rational advices without prejudice about CTM therapies.

Key Words: Children, hematology, herbal medicine, nutrient supplement, complementary and traditional medicine.

\section{GíRIŞ}

Tamamlayıcı ve geleneksel tıp (TGT), modern tıbbi tedavinin yanında tedavi başarısının artırılması ve yan etkilerin azaltılması için besinlerin, fiziksel uygulamaların veya dini yöntemlerin kullanılmasıdır $(1,2)$. Çocukluk çağı döneminde kanser tanısı almış hastalarda TGT tedavileri kullanım siklığ $\% 31-84$ arasında bildirilmektedir (3). Kanser dışında astım, diabetes mellitus, epilepsi, orak hücreli anemi ve talasemi gibi kronik hastalarda da aileler TGT tedavilerine başvurabilmektedir (4). TGT tedavileri içinde en sık kullanılanlar bitkisel tedaviler ve besin desteği (şifalı otlar, hayvansal ürünler, vitaminler, konsantre yiyecekler gibi) olarak bilinmektedir (2). TGT amacıyla kullanılan ürünlerin çeşitliliği toplumlara göre büyük farklilıklar göstermektedir (5-8). Özellikle bitkisel takviye ilaçların böbrek yetmezliği, hipertansiyon, karaciğer yetmezliği, nöbet ve venooklusif hastalık gibi yan etkileri görülebilir (1). Sistemik dolaşıma geçen bu ürünlerin kullanımı, hastaların kullandığı ilaçlarla etkileşime girme riskini de doğurmaktadır. Çocukluk yaş grubundaki hematoloji/onkoloji hastalar1, hem bu grupta TGT tedavilerinin yaygın kullanılması hem de kullandıkları TGT ürünleri ile etkileşime geçebilecek birçok ilaç kullanmaları nedeniyle hassas bir hasta grubunu oluşturmaktadır (7). Çocukluk çağında az sayıda çalışmada genellikle kanser hastalarında TGT ürünü kullanımı incelenmiş̧ir (1, 5-7). Çalışmamızda Çocuk Hematoloji Kliniği'nde izlenen beniyn ve maliyn hastalık tanılı hastaların TGT ürünü olarak kullandıkları besin alışkanlıklarını ve alışkanlıkları ile ilişkili faktörleri incelemeyi amaçladık.

\section{GEREÇ ve YÖNTEM}

Çalışmamız Hacettepe Üniversitesi Tıp Fakültesi Çocuk Hematoloji Kliniği'nde takip edilen hematolojik kanser veya kronik hematolojik hastalığı olan hastalar ile gerçekleştirildi. Çalışmaya kliniğimizde izlenen, $1-20$ yaş arasındaki hastalar dahil edildi. Ocak 2014 ve Ocak 2016 tarihleri arasında hastaların ebeveynlerine çalışma anketi verilerek doldurmaları istendi, katılımcılardan çalışmaya katılım için sözel onay alındı. Çalışma anketinin birinci kısmında hastaların demografik özellikleri ve anne babalarının eğitim düzeleri ile ilgili sorular vardı. Anketin devamında TGT ürünü kullanıp kullanmadıkları soruldu, kullananlar için sık kullanılan besin ürünleri şıklar halinde verildi ve bir açık uçlu soruyla şıklarda bulunmayan bir ürün kullandılarsa onu da belirtmeleri istendi. Ürünün paket özellikleri, hastaların ürünü kullanmaya nasıl karar verdikleri, nereden elde ettikleri, ne kadar ödedikleri, hekimlerine danışıp danışmadıkları, üründen fayda veya zarar görüp görmedikleri hakkındaki düşünceleri soruldu. Ürün maliyeti, çalışmanın yapıldığı dönemdeki ortalama dolar kuruna göre dolar cinsinden hesapland. İstatistiksel analiz için SPSS versiyon 21 programı kullanıldı. Tanımlayıcı istatistiksel analizlerle veriler incelendi, gruplar arası sıklık fark1 Ki-kare testi ile değerlendirildi.

\section{BULGULAR}

Çalışmaya alınan 138 hastanın yaş ortancası 9 $(1-20)$ y1ld1. Hastaların 81'i akut lenfoblastik lösemi, beşi kronik myeloid lösemi, dördü akut myeloid lösemi, biri juvenil myeloid lösemi, 14'ü talasemi majör, ikisi talasemi intermedia, sekizi idiyopatik trombositopenik purpura, beşi hemofili A, üçü trombofili, ikisi demir eksikliği anemisi, ikisi sferositoz ve birer hasta da Diamond Blackfan anemisi, Fanconi anemisi, Gorham sendromu, konjenital diseritropoetik anemi, mastoisitoz, nötropeni, orak hücreli anemi, otoimmün hemolitik anemi, paroksismal nokturnal hemoglobinüri, trombositoz ve von Willebrand hastalığ 1 tanılarıyla izlenmekteydi. Hastaların 91'i $(\% 65,9)$ maliyn bir tanıya sahipken 47 'si 
$(\% 34,1)$ beniyn bir tanıla izlenmekteydi. Yetmiş bir $(\% 51,4)$ hasta en az bir TGT beslenme ürünü kullanırken $67(\% 48,6)$ hasta böyle bir ürün hiç kullanmamıştı. TGT beslenme ürünü kullananların 47'si sadece bir ürün, 20'si iki ve dördü üç ürün kullanmıştı. Toplamda 21 çeşit ürün kullanıldığı öğrenildi. Kullanım sıklığına göre ürünler şunlardı; keçiboynuzu pekmezi (39 hasta), arı sütü (13 hasta), üzüm çekirdeği ekstresi (9 hasta), üzüm pekmezi ( 7 hasta), polen (6 hasta), 1sirgan otu (4 hasta), propolis (4 hasta), çörek otu (2 hasta), kestane balı (2 hasta), maydonoz suyu (2 hasta) ve birer hastada ada çayı, bal, balık yağı, bitkisel demir şurubu, e vitamini desteği, elma suyu, kapari reçeli, kaplumbağa kanı, kemik suyu, köpek balığı eti, papatya. Hastaların 27'sinin (\%38) bu ürünleri doktorlarının bilgisi dişında kullandığ öğrenildi (Tablo 1). Ürünlerin temin edildiği yerler; 44 hastada $(\% 56,3)$ aktar, 13 hastada $(\% 18,3)$ tanıdık birileri, 11 hastada $(\% 15,5)$ eczane, dört hastada $(\% 5,6)$ internet ve üç hastada $(\% 4,2)$ yurt dişı bir yerdi. Ürünlerin \%79,4'ü paketli, \%20,6's1 açık olarak temin edilmişti. İlgili bakanlıklar tarafindan onaylanmış ürünlerin kullanımı \%69,1 iken $\% 8,8$ 'i onaysızd1, $\% 22,1$ 'inde ise ailelerin onay durumu hakkında bilgisi yoktu. Kullanılan ürünlerin ortanca maliyeti $12,2(0-1224)$ dolard1. Hasta anne babalarının sadece biri $(\% 1,4)$ kullanılan ürüne ikincil olumsuz bir etki gördügünü belirtirken, 43'ü $(\% 60,6)$ ürünlerden fayda gördüğüne inanmaktaydı. Olumsuz etki görülen hastaya köpek balığ 1 eti yedirilmişti ve bu dönemde karaciğer fonksiyon testlerinde 40 kat artış olması nedeniyle kemoterapi tedavisine ara verilmişti.

Anne babalarının eğitim düzeyi incelendiğinde 129 'u soruya cevap verdi, cevap verenlerin 58'inde $(\% 45)$ anne veya babadan en az biri üniversite mezunu, 71'i (\%55) ise daha alt bir eğitim kurumundan mezundu. Hastaların anne ve babalarının eğitim düzeyine göre TGT beslenme ürünü kullanma sıklığı karşılaştırıldığında üniversite mezunu anne babaların çocuklarında ürün kullanımı \%56,9 iken daha düşük eğitim düzeyi anne babalarda kullanım \%50,7 idi, iki grup arasinda istatistiksel olarak fark yoktu ( $p$; 0,48 ) (Tablo 2). Hasta tanılarının beniyn veya maliyn olasına göre beslenme ürünü ve bitkisel tedavi kullanımı karşılaştırıldığında istatistiksel olarak anlamlı şekilde maliyn tanılı hastalarda beniynlere göre kullanımın daha fazla olduğu görüldü (sırasıyla; \%61,5, \%31,9, $p ; 0,001$ ) (Tablo 2).

\section{TARTIŞMA}

Tamamlayıcı ve geleneksel tıp uygulamaları, güncelliğini tüm dünyada sürdürmektedir. Zaman ve bölgeye göre kullanılan yöntemler ve yöntemlerin sıklığ 1 değişmektedir. Ülkemiz Avrupa ülkeleri içerisinde çocukluk çağında TGT uygulamalarının en sik kullanıldığ ülkelerden birisidir (8). Türkiye'den yapılan bazı çalışmalarda da diğer ülkelerle benzer şekilde çocukluk çağında en sik kullanılan TGT uygulamaları beslenme ürünleri ve bitkisel tedavilerinin kullanımı olarak bildirilmiştir $\quad(9, \quad 10)$ C Çalışmamızda kliniğimizde takip edilen beniyn ve maliyn hastalık tanılı hematoloji hastalarında TGT beslenme ürünü ve bitkisel tedavi kullanımı sıklığını \%51,4 olarak bulduk. Turhan ve arkadaşlarının Eskişehir'de 74 çocuk onkoloji hastası ile yaptıkları çalışmalarında hastalarının \%67,5'inde TGT uygulaması olarak bitkisel tedavi ve beslenme ürünü kullandığını bildirmişlerdir (1). Bu çalışmada en sık kullanılan ürünler sırasıyla üzüm pekmezi, 1sırgan otu ve kaplumbağa kanı çıkmıştır. Türkiye'den yapılan başka bir çalışmada çocukluk yaş grubundaki talasemi tanılı hastalarda beslenme ürünü desteği kullanım sıklığ $1 \% 47,4$, en sik kullanılan iki ürün ise keçiboynuzu ve üzüm pekmezi olarak bulunmuştur (4). Çalışmamızda hastaların birçok farklı ürün kullandığını gördük. En sık kullanılan beş ürün ise keçiboynuzu pekmezi, ar1 sütü, üzüm çekirdeği ekstresi, üzüm pekmezi ve polendi. Pekmezin bizim çalışmamızda da sık kullanılan bir ürün olarak öne çıkması ülkemizde anne babaların pekmeze atfettikleri enerji verici ve anemiyi iyileştirici etkisi olabilir. Ülkemizde hasta olmayan çocuklarda da anne babalar pekmez tüketimine önem vermekte kahvaltıda çocuklarından sağliklı olabilmeleri için pekmez içmelerini istemektedirler $(4,9)$. Antalya (2001) ve Erzurum'da (2003) bulunan merkezlerden yapılan iki çalışmada kanser hastalarında en sik kullanılan TGT beslenme ürünü 1sırgan otu olarak bildirilmiştir $(11,12)$. Eskişehir'den (2016) çocuk onkoloji hastaları ile yapılan çalışmada ise 1sırgan otu en sık kullanılan ikinci ürün çıkmıştır (1). Ankara'da 2003 yılında çocukluk çağ 1 astım hastaları ile yapılan çalışmada bıldırcın yumurtası en sık 
kullanılan TGT beslenme ürünü (13), Antalya'da (2012) çocukluk çağındaki talasemi hastaları incelendiğinde ise en sık kullanılan üçüncü ürün bildırcın yumurtası olarak bildirilmiştir (4). Bizim çalışmamızda ise ısırgan otu sadece 4 hastada kullanılmış, bıldırcın yumurtası ise kullanılan ürünler arasına girmemiştir. $\mathrm{Bu}$ sonuçlar bölgesel farkl11ık olabileceği gibi farklı dönemlerde beslenme ürünlerinin kullanım eğiliminin değişebileceğini göstermektedir.

Çalışmamızda hastalarda maliyn ve beniyn tanı olmasına göre TGT beslenme ürünlerinin kullanım sıklı̆̆ını karşılaştırdığımızda istatistiksel olarak anlamlı şekilde maliyn tanılı hastalarda bu ürünlerin kullanımının daha sık olduğunu gördük (Tablo 2). Maliyn tanılı hastalarda hastalığın daha ciddi ve tehlikeli olması ve kemoterapinin yan etkilerinden korunma isteği aileleri farklı arayışlara itmiş olabilir. Bizim sonuçlarımızın aksine Sanchez ve arkadaşlarının çalışmasında çocuk onkoloji hastaları ve orak hücreli anemi tanılı hastaların bitkisel tedavi ve beslenme ürünü kullanım sıklığı arasında fark bulunmamıştır (7). Bu fark çalışmamızdaki maliyn tanılı hastaların hepsinin tanısının lösemi olması ve bu nedenle diğer onkolojik tanılara göre daha ağır kemoterapi rejimleri almaları, tedavi komplikasyonlarının ağır olmas1 ve ailelerin daha fazla destekleyici tedaviye ihtiyaç duymaları ile açıklanabilir. Ladas ve arkadaşlarının çalışmasında da lösemi tanılı çocuk hastalarda diğer solid tümör tanılı hastalara göre bitkisel tedavi kullanımının daha sık olduğu gösterilmiştir (5).

Anne babaların eğitim düzeyi ile TGT beslenme ürünleri ve bitkisel tedavilerin kullanımı sıklığını incelediğimizde anne ve babasından en az biri üniversite düzeyinde eğitim görmüş hastalarla diğerleri arasında fark olmadığını gördük. İskoçya'dan yapılmış bir çalışmada ise sosyoekonomik düzeyi en yüksek olanların en düşük olanlara göre TGT tedavisi kullanmaya 4,6 kat daha yatkın oldukları gösterilmiştir (6). Ülkemizden çocuk onkoloji hastaları ile yapılan bir çalışmada ise bitkisel tedavi ve beslenme/vitamin desteği kullanımı ile anne-baba eğitim düzeyi arasında ilişki kurulamamıştır.

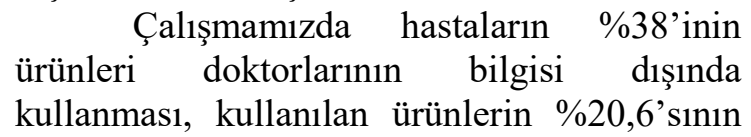

paketsiz olması ve çocuklarına ürün kullanan anne babaların ancak \%69,1'inin ürünün ilgili bakanlıklar tarafından onaylı olduğunu bilmesi hastaların bir kısmının güvenli olmayan ürün kullanımı açısından risk altında olduğunu göstermektedir. Çocuk hematoloji-onkoloji hastaları ile yapılan daha önceki çalışmalarda da hastaların \%50 - 87'ye varan çoğunluğuna doktorlarının bilgisi dişında TGT tedavileri kullanıldığ 1 bildirilmiştir $(5,7)$. Çocuk hematoloji-onkoloji kliniklerinde çalışan doktorlarin rutin takiplerde hasta ailelerine TGT ürünü kullanıp kullanmadıklarını sormaları hastaların riskli bir ürünü kullanmalarının önlenmesi için faydalı olabilir. Bitkisel tedavilerin ve beslenme ürünlerinin s1k kullanılması hastalara uygulanan ilaçlara gelişebilecek etkileşimler açısından dikkatli olmayı gerektirmektedir. Çalışmamızda hasta ailelerinin \%60,6's1 kullandıklar1 TGT ürününden fayda gördüğünü düşünürken sadece bir hastanın $(\% 1,4)$ anne babas1 kullandıkları ürünle ilişkili bir yan etki geliştiğini belirtmiştir. Yan etki gelişen hastaya köpek balığı eti yedirilmiş ve hastanın karaciğer fonksiyon testlerinin yükselmesi nedeniyle kemoterapisine ara verilmişti. Çalışmamızda hastalara köpek balığı eti ve kaplumbağa kanı gibi gündelik tüketimi olmayan ürünler verildiği gibi normal beslenme öğünlerinde de kullanılabilen pekmez, bal gibi gıdalar hastalarca daha çok tüketilmiştir. Bu konuda Uluslararası Çocuk Onkoloji Derneği'nin (International Society of Pediatric Oncology; SIOP) sağlık çalışanları için önerileri şunlardır: hastalara ve anne babalarına fiziksel ve psikolojik zararı dokunabilecek TGT tedavilerine karşı dikkatli olunmalı, ancak zararı olmayan tamamlayıc1 tıp tedavileri küçük görülüp otomatik olarak reddedilmemelidir $(2,14)$.

Sonuç olarak çocukluk çağında hematoloji hastaları arasında özellikle maliyn bir taniya sahip olanlarda bitkisel tedavi ve beslenme desteği kullanımı sıktır ve bir kısmından hastaların sorumlu doktorlarının da haberi yoktur. Hastaların kliniklerde takiplerinde bu tür destekler alıp almadıklarının rutinde sorulmalı, hastaların kullandıkları ürünler hakkında önyargıdan uzak rasyonel öneriler verilmelidir.

Çıkar Çatışması: Yok. 


\section{Orijinal Çalışma}

Tablo 1:Tamamlayıcı ve geleneksel tıp beslenme desteği ve bitkisel tedavi olarak kullanılan ürünlerin genel özellikleri

\begin{tabular}{|c|c|c|}
\hline \multirow{3}{*}{ Ürün kullanımı: } & & $\mathrm{n}(\%)$ \\
\hline & Var & $71(51,4)$ \\
\hline & Yok & $67(48,6)$ \\
\hline \multirow[t]{2}{*}{ Doktora sorma: } & Evet & $44(62)$ \\
\hline & Hayır & $27(38)$ \\
\hline \multicolumn{3}{|c|}{ Ürünün temin edildiği yer } \\
\hline \multicolumn{2}{|c|}{ Aktar } & $40(56,3)$ \\
\hline \multicolumn{2}{|l|}{ Tanıdıktan } & $13(18,3)$ \\
\hline \multicolumn{2}{|l|}{ Eczaneden } & $11(15,5)$ \\
\hline \multirow{2}{*}{\multicolumn{2}{|c|}{$\begin{array}{l}\text { Internet } \\
\text { Yurt dişından }\end{array}$}} & $4(5,6)$ \\
\hline & & $3(4,2)$ \\
\hline \multirow[t]{2}{*}{ Paketli ürün mü?* } & Evet & $54(79,4)$ \\
\hline & Hayır & $14(20,6)$ \\
\hline \multirow[t]{2}{*}{ Olumsuz etki: } & Var & $1(1,4)$ \\
\hline & Yok & $70(98,6)$ \\
\hline \multirow[t]{2}{*}{ Olumlu etki: } & Var & $43(60,6)$ \\
\hline & Yok & $28(39,4)$ \\
\hline
\end{tabular}

*68 kat1lımc bu soruya cevap verdi

Tablo 2: Tamamlayıcı ve geleneksel tıp beslenme desteği ve bitkisel tedavi kullanım sıklığının karşılaştırılması

\begin{tabular}{|c|c|c|c|}
\hline & \multicolumn{2}{|c|}{ TGT beslenme ürünü kullanımı } & \multirow[t]{2}{*}{$p$} \\
\hline & Var & Yok & \\
\hline Üniversite mezunu anne-baba: Evet & $33(\% 56,9)$ & $25(\% 43,1)$ & \multirow[t]{2}{*}{0,48} \\
\hline Hayır & $36(\% 50,7)$ & $35(\% 49,3)$ & \\
\hline Maliyn hastalık & $56(\% 61,5)$ & $35(\% 38,5)$ & \multirow[t]{2}{*}{0,001} \\
\hline Beniyn hastalık & $15(\% 31,9)$ & $32(\% 68,1)$ & \\
\hline
\end{tabular}

\section{REFERANSLAR}

1. Turhan $\mathrm{AB}$, Bor $\mathrm{O}$. Use of herbs or vitamin/mineral/nutrient supplements by pediatric oncology patients. Complement Ther Clin Pract 2016; 23: 69-74

2. Kelly KM. Integrative therapies for children with hematological malignancies. Hematology Am Soc Hematol Educ Program 2009: 307-312

3. Kelly KM. Complementary and alternative medical therapies for children with cancer. Eur J Cancer 2004; 40: 2041-2046

4. Efe E, Isler A, Sarvan S, Baser H, Yesilipek A. Complementary and alternative medicine use in children with thalassaemia. J Clin Nurs 2013; 22: 760-769

5. Ladas EJ, Rivas S, Ndao D, Damoulakis D, Bao YY, Cheng B, et.al. Use of traditional and complementary/alternative medicine (TCAM) in children with cancer in Guatemala. Pediatr Blood Cancer 2014; 61: 687-692

6. Revuelta-Iniesta R, Wilson ML, White K, Stewart L, McKenzie JM, Wilson DC. Complementary and alternative medicine usage in Scottish children and adolescents during cancer treatment. Complement Ther Clin Pract 2014; 20: 197-202

7. Sanchez HC, Karlson CW, Hsu JH, Ostrenga A, Gordon C. Complementary and Alternative Medicine Use in Pediatric Hematology/Oncology Patients at the University of Mississippi Medical Center. J Altern Complement Med 2015; 21: 660-666
8. Zuzak TJ, Bonkova J, Careddu D, Garami M, Hadjipanayis A, Jazbec J, et. al. Use of complementary and alternative medicine by children in Europe: published data and expert perspectives. Complement Ther Med 2013; 21 Suppl 1: S34-47

9. Karadeniz C, Pinarli FG, Oguz A, Gursel T, Canter B. Complementary/alternative medicine use in a pediatric oncology unit in Turkey. Pediatr Blood Cancer 2007; 48: 540-543

10. Ozturk C, Karayagiz G. Exploration of the use of complementary and alternative medicine among Turkish children. J Clin Nurs 2008; 17: 2558-2564

11. Gozum S, Tezel A, Koc M. Complementary alternative treatments used by patients with cancer in eastern Turkey. Cancer Nurs 2003; 26: 230-236

12. Samur M, Bozcuk HS, Kara A, Savas B. Factors associated with utilization of nonproven cancer therapies in Turkey. A study of 135 patients from a single center. Support Care Cancer 2001; 9: 452-458

13. Orhan F, Sekerel BE, Kocabas CN, Sackesen C, Adalioglu G, Tuncer A. Complementary and alternative medicine in children with asthma. Ann Allergy Asthma Immunol 2003; 90: 611-615

14. Jankovic M, Spinetta JJ, Martins AG, Pession A, Sullivan M, D'Angio GJ, et. al. Non-conventional therapies in childhood cancer: guidelines for distinguishing non-harmful from harmful therapies: a report of the SIOP Working Committee on Psychosocial Issues in Pediatric Oncology. Pediatr Blood Cancer 2004; 42: 106-108 